\title{
Feasibility of Best Management Practices of Cotton as Perceived by Farmers in Nalgonda District of Telangana, India
}

\author{
Shaik. Neema Parveen* and V. Sudha Rani \\ Department of Agricultural Extension, College of Agriculture, Professor Jayashankar Telangana \\ State Agricultural University, Rajendranagar, Hyderabad- 500030, Telangana, India \\ *Corresponding author
}

\section{A B S T R A C T}

\begin{tabular}{|l|}
\hline Ke y w o r d s \\
Feasibility, Best \\
Management \\
Practices, \\
Attributes, Cotton. \\
\hline Article Info \\
\hline $\begin{array}{l}\text { Accepted: } \\
\text { 10 September } 2017 \\
\text { Available Online: } \\
\text { 10 October } 2017\end{array}$ \\
\hline
\end{tabular}

The present investigation was carried out in Nalgonda district of Telangana with 120 cotton farmers as respondents. Ex-post facto research design was followed in the investigation. The respondents were selected at random from four villages of two mandals of the district. Feasibility was determined using perceived feasibility index (PFI). Seven attributes such as suitability, profitability, complexity, observability, compatibility, cost, trialability were used to determine perceived feasibility for each practice. The results showed that majority $(66.66 \%)$ of the cotton growers perceived overall best management practices as moderately feasible followed by highly feasible (17.5\%) and less feasible $(15.84 \%)$ respectively. Practices such as spacing, intercropping, nutrient management, weed management, insect pest management, harvest and post-harvest management were perceived as moderately feasible by majority of the farmers. Irrigation at critical stages was perceived as highly feasible. Low perceived feasibility was observed with respect to disease management practices.

\section{Introduction}

Since the dawn of civilizations agriculture is one sector that impacts and in turn is impacted the most by environment. Hence sustainability of the human race and world depends a lot on environment friendly agriculture. During the past fifty years, agricultural development policies have been remarkably successful at emphasizing external inputs as the means to increase food production. These external inputs have substituted for natural processes and resources, rendering them less powerful and dangerous to the environment. The basic challenge for sustainable agriculture is to make better use of these natural resources.
This can be done by minimizing the external inputs use and by regenerating internal resources more effectively, or by combinations of both. Evidence is now emerging that regenerative and resourceconserving technologies and practices can bring both environmental and economic benefits for farmers, communities, and nations.

Cotton is the oldest among all fibres, and one of the most important commercial crops playing a key role in the world economy. It is one of the most important fibre and cash crops of India and plays a dominant role in 
the industrial and agricultural economy of the country. Being a cash crop, cotton is known for its intensive cultivation. The focus on high yield production, without taking agriculture and environmental sustainability into account, has become standard practice. After few years of introduction of $\mathrm{Bt}$ cotton the pesticide use has again increased due to increased incidence of sucking pests.

Addressing to the various issues, many concepts have been developed under sustainable cotton cultivation. Best management practices (BMPs) are one among such concepts. Best Management Practices (BMPs) are agricultural practices which optimize the three pillars of sustainability. The three pillars include social responsibility, environmental integrity and economic viability by binding together, the financial requirements for agriculture, such as high yield with environmental and social concerns, such as water and pesticide use.

Technically speaking these practices focus on right quantity, right time and right method of application of inorganic inputs supplemented by organic resources. Keeping all this in view, the present study was conducted with an objective to determine level of perceived feasibility of best management practices in cotton.

\section{Materials and Methods}

The study was conducted in Nalgonda district with a sample of 120 cotton farmers. Ex-post facto research design was followed. The respondents were selected from four villages of two mandals of the district at random. List of best management practices in cotton from the book "Best Management Practices in Agricultural Crops" published and released by Professor Jayashankar Telangana State Agricultural University (formerly ANGRAU) were prepared initially. After consultation with subject matter specialists, 9 important best management practices were identified pertaining to the study area. A schedule was developed to measure the feasibility of important best management practices. Feasibility was operationalised as the degree to which a recommended best management practice can be adopted or practiced by an individual farmer in a given farming system. It was measured in terms of seven perceived attributes such as suitability, profitability, complexity, observability, compatibility, cost and trialability. It was arrived at by using the perceived feasibility index developed by Mano Sihag and Achla Malaviya (1990) with slight modifications.

Responses were measured by using threepoint continuum for each of the perceived attribute against each practice as high, medium and low and the scores were given as 3, 2, 1 for the positive attribute and 1,2, 3 for the negative attribute respectively.

Formula used for measuring perceived feasibility index

$$
\mathrm{PFI}=\frac{\mathrm{E}(\mathrm{S}+\mathrm{Pr}+\mathrm{CoM}+\mathrm{O}+\mathrm{Cx}+\mathrm{Co}+\mathrm{Tr})}{\mathrm{P}(\mathrm{S}+\mathrm{Pr}+\mathrm{CoM}+\mathrm{O}+\mathrm{Cx}+\mathrm{Co}+\mathrm{Tr})}
$$

Where,

PFI $=$ Perceived feasibility index

$\mathrm{E}=$ Extent to which innovation was perceived field feasible by the respondents with respect to Suitability (S), Profitability (Pr), Compatibility (CoM), Observability (O), Complexity (Cx), Cost (Co), Trialability (Tr).

$\mathrm{P}=$ Maximum limit to which innovation was perceived field feasible with respect to Suitability (S), Profitability (Pr), Compatibility (CoM), Observability (O), Complexity (Cx), Cost (Co), Trialability (Tr). 


\section{Results and Discussion}

From Table 1 it can be seen that the majority $(66.66 \%)$ of the cotton growers perceived overall best management practices as moderately feasible followed by highly feasible $(17.5 \%)$ and less feasible $(15.84 \%)$ respectively.

\section{Practice wise perceived feasibility}

\section{Soils}

Suitability was the only attribute that was found relevant to measure the feasibility of this recommended practice in the present study. Results showed that majority $(80.84 \%)$ of the farmers perceived soils as moderately suitable followed by 19.16 per cent of the farmers who perceived soils as highly feasible (Table 2).

\section{Spacing}

It could be observed from Table 3 that majority $(88.33 \%)$ of the respondents perceived spacing as moderately feasible followed by highly feasible as perceived by 11.66 per cent of the respondents.

\section{Intercropping}

Table 4 indicates that less than half $(47.5 \%)$ of the respondents perceived intercropping as moderately feasible followed by less feasible $(25 \%)$, very highly feasible (15\%), highly feasible (10.84\%) and very less feasible $(1.66 \%)$. This trend in perceived feasibility was observed because there was moderate to less perceived trialability, perceived compatibility and less perceived profitability by most of the respondents.

\section{Irrigation at critical stages}

It can be seen from Table 5 that most $(46.67 \%)$ of the respondents perceived irrigation as highly feasible followed by moderately feasible (20.84\%), very high feasible $(13.33 \%)$, less feasible $(11.66 \%)$ and very less feasible (7.5\%). The probable reason for high perceived feasibility for irrigation may be due to its high perceived trialability and perceived observability.

\section{Nutrient management}

It can be observed that less than half $(42.5 \%)$ of the respondents perceived nutrient management practices as moderately feasible followed by less feasible (26.67\%), very less feasible $(20.83 \%)$ and highly feasible $(9.99 \%)$. The less perceived feasibility of overall nutrient management practices could be because of moderate to less perceived feasibility of practices such as split application of $\mathrm{N}$ and $\mathrm{K}$, application of FYM/ bio fertilizers/organic manures, foliar application of nutrients and correction of micro nutrient deficiencies which were components under nutrient management (Table 6).

Table.1 Distribution of respondents based on their overall perceived feasibility index

\begin{tabular}{|l|l|l|l|}
\hline S.No & Category & Frequency & Percentage \\
\hline 1. & Low $(<60.53)$ & 19 & 15.84 \\
\hline 2. & Medium $(60.53-69.27)$ & 80 & 66.66 \\
\hline 3. & High $(>69.27)$ & 21 & 17.5 \\
\hline
\end{tabular}


Table.2 Distribution of respondents based on their perceived feasibility of soils

\begin{tabular}{|l|l|l|l|}
\hline S.No & Category & Frequency & Percentage \\
\hline 1. & Low $(<59.88)$ & 0 & 0 \\
\hline 2. & Medium $(59.88-86.22)$ & 97 & 80.84 \\
\hline 3. & High $(>86.22)$ & 23 & 19.16 \\
\hline
\end{tabular}

Table.3 Distribution of respondents based on their perceived feasibility of spacing

\begin{tabular}{|l|l|l|l|}
\hline S.No & Category & Frequency & Percentage \\
\hline 1. & Low $(<65.63)$ & 0 & 0 \\
\hline 2. & Medium $(65.63-76.37)$ & 106 & 88.33 \\
\hline 3. & High $(>76.37)$ & 14 & 11.67 \\
\hline
\end{tabular}

Table.4 Distribution of respondents based on their perceived feasibility of intercropping

\begin{tabular}{|l|l|l|l|}
\hline S.No & Category & Frequency & Percentage \\
\hline 1. & Very low (38-44.6) & 2 & 1.66 \\
\hline 2. & Low (44.6-51.2) & 30 & 25 \\
\hline 3. & Medium $(52.2-57.8)$ & 57 & 47.5 \\
\hline 4. & High $(57.8-64.4)$ & 13 & 10.84 \\
\hline 5. & Very high $(64.4-71)$ & 18 & 15 \\
\hline
\end{tabular}

Table.5 Distribution of respondents based on their perceived feasibility of irrigation at critical stages

\begin{tabular}{|l|l|l|l|}
\hline S.No & Category & Frequency & Percentage \\
\hline 1. & Very low $(47.62-53.34)$ & 9 & 7.5 \\
\hline 2. & Low $(53.34-59.06)$ & 14 & 11.66 \\
\hline 3. & Medium $(59.06-64.78)$ & 25 & 20.84 \\
\hline 4. & High $(64.78-70.5)$ & 56 & 46.67 \\
\hline 5. & Very high $(70.5-76.22)$ & 16 & 13.33 \\
\hline
\end{tabular}

Table.6 Distribution of respondents based on their perceived feasibility of nutrient management practices

\begin{tabular}{|l|l|l|l|}
\hline S.No & Category & Frequency & Percentage \\
\hline 1. & Very low $(54.29-61.91)$ & 25 & 20.83 \\
\hline 2. & Low $(61.91-69.53)$ & 32 & 26.67 \\
\hline 3. & Medium $(69.53-77.15)$ & 51 & 42.5 \\
\hline 4. & High $(77.15-84.77)$ & 12 & 10 \\
\hline
\end{tabular}


Table.7 Distribution of respondents based on their perceived feasibility of weed management practices

\begin{tabular}{|l|l|l|l|}
\hline S.No & Category & Frequency & Percentage \\
\hline 1. & Very low (53.09-59.57) & 20 & 16.67 \\
\hline 2. & Low (59.57-66.05) & 16 & 13.33 \\
\hline 3. & Medium $(66.05-72.53)$ & 48 & 40 \\
\hline 4. & High $(72.53-79.01)$ & 36 & 30 \\
\hline
\end{tabular}

Table.8 Distribution of respondents based on their perceived feasibility of insect pest management practices

\begin{tabular}{|l|l|l|l|}
\hline S.No & Category & Frequency & Percentage \\
\hline 1. & Very low (59.05-64.19) & 8 & 6.66 \\
\hline 2. & Low (64.19-69.33) & 34 & 28.34 \\
\hline 3. & Medium $(69.33-74.77)$ & 56 & 46.66 \\
\hline 4. & High $(74.47-79.61)$ & 22 & 18.34 \\
\hline
\end{tabular}

Table.9 Distribution of respondents based on their perceived feasibility of disease management practices

\begin{tabular}{|l|l|l|l|}
\hline S.No & Category & Frequency & Percentage \\
\hline 1. & Low $(41.27-49.73)$ & 66 & 55 \\
\hline 2. & Medium $(49.73-58.19)$ & 36 & 30 \\
\hline 3. & High $(58.19-66.67)$ & 18 & 15 \\
\hline
\end{tabular}

Table.10 Distribution of respondents based on their perceived feasibility of harvest and postharvest management practices

\begin{tabular}{|l|l|l|l|}
\hline S.No & Category & Frequency & Percentage \\
\hline 1. & Low $(<53.43)$ & 23 & 19.16 \\
\hline 2. & Medium $(53.43-63.29)$ & 67 & 55.84 \\
\hline 3. & High $(>63.29)$ & 30 & 25 \\
\hline
\end{tabular}

\section{Weed management}

It was observed from the study that less than half $(40 \%)$ of the respondents perceived weed management practices as moderately feasible followed by highly feasible $(30 \%)$, very less feasible $(16.67 \%)$ and less feasible $(13.33 \%)$ as evident from Table 7. Perceived feasibility of pre-emergence weedicide application was found to be high among different components under weed management.

\section{Insect pest management}

From the Table 8 , it can be observed that less than half $(46.66 \%)$ of the respondents perceived pest management practices as moderately feasible followed by less feasible (28.34\%), highly feasible (18.34\%) and very less feasible (6.66\%). Further it was revealed that majority of the respondents' perceived practices like stem application, barrier/trap crops as less feasible, yellow sticky traps and 
application of NSKE as moderately feasible, application of insecticides as highly feasible. However, it is to be noted that with regard to application of insecticides responses given by the farmers were not according to economic threshold level based insecticide application as indicated under best management practices. The perceived feasibility is reported to be high, because of perception of farmers that increased insecticide application will kill the pests effectively.

\section{Disease management}

It was observed that majority (55\%) of the respondents perceived disease management practices as less feasible followed by medium $(30 \%)$ and highly feasible (15\%) respectively (Table 9). The less perceived feasibility was due to lack of adequate knowledge, skill on disease management practices, more perceived complexity in understanding and application in the field and less perceived observability. The similar trend in less perceived feasibility of seed treatment practices was observed by Narendra Nath Dutt (1999).

\section{Harvest and post-harvest management}

It is evident from Table 10 that majority $(55.84 \%)$ of the respondents perceived harvest and post-harvest management practices as moderately feasible followed by highly feasible $(25 \%)$ and less feasible $(19.16 \%)$ respectively. Adoption of a technology or a practice depends to a larger extent on how far it is feasible in farmer's point of view. Hence assessment of feasibility of a practice as perceived by the farmers is most important. In the present study moderate level of perceived feasibility was observed when overall best management practices were considered. Low perceived feasibility was seen in disease management practices. This indicates that majority of the farmers did not find management of diseases as an important component under cotton cultivation. The reason might be lack of ability to diagnose the diseases on the part of the farmers and lack of sufficient skills on practices like seed treatment, soil application etc. This states that there is a need for capacity building of the farmers on identification of diseases in their fields and management of the same.

\section{References}

Best Management Practices in Agricultural Crops. 2013. Directorate of Extension, Acharya N.G. Ranga Agricultural University, Rajendranagar, Hyderabad.

Mano Sihag and Achla Malaviya. 1990. Perceived feasibility of including soakage pit in rural areas. Maharastra Journal of Extension Education. 9: 2428.

Narendranath Dutt, K., 1999. A study on the suitability and feasibility of critical chillicrop production technology in Khammam district of Andhra Pradesh. M.Sc. Thesis submitted to Acharya N.G. Ranga Agricultural University, Hyderabad, India.

\section{How to cite this article:}

Shaik. Neema Parveen and Sudha Rani, V. 2017. Feasibility of Best Management Practices of Cotton as Perceived by Farmers in Nalgonda District of Telangana. Int.J.Curr.Microbiol.App.Sci. 6(10): 910-915. doi: https://doi.org/10.20546/ijcmas.2017.610.109 